\title{
Aggression and dominance in cichlids in resident-intruder tests: the role of environmental enrichment
}

\author{
Vincent Nijman ${ }^{1}$ and Boudewijn A. Heuts ${ }^{2}$
}

When establishing dominance residents have a greater likelihood to dominate intruders than vice versa, partially because the resident has more to loose that the intruder has to win. This is known as the prior residency effect. In environmentally rich environments this effect should be stronger than in poor environments. Recently Kadry \& Barreto (2010, Neotrop Ichthyol 8: 329-332) tested this in the pearl cichlid Geophagus brasiliensis (17 test pairs) and reported that environmental enrichment led to a reduction of aggression. We here present data on four other cichlids (332 test pairs) showing a stronger prior residency effect in enriched conditions, and, for two species, an increase in aggression. We discuss possible reasons for the differences between studies, focussing on the relationship between aggression and dominance and sample size effects.

No estabelecimento de dominancia, residentes têm uma maior probabilidade de dominar os intrusos que vice-versa, em parte porque o residente tem mais a perder que o invasor tem a ganhar. Isto é conhecido como o efeito de residência prévia. Em ambientes ecologicamente ricos esse efeito deve ser mais forte do que em ambientes pobres. Recentemente Kadry \& Barreto (2010, Neotrop. Ichthyol. 8: 329-332) testaram isso no cará Geophagus brasiliensis (17 pares de teste) e relataram que o enriquecimento ambiental levou a uma redução de agressão. Aqui apresentamos dados de quatro outros ciclídeos (332 pares de teste), mostrando um efeito mais forte de residência prévia em condições enriquecidas, e, para duas espécies, o aumento da agressão. Discutimos possíveis razões para as diferenças entre os estudos, concentrando-nos sobre a relação entre agressão e dominação e os efeitos do tamanho da amostra.

Key words: Environmental enrichment, Pay-off asymmetry hypothesis, Prior residency effect, Resource holding power, Territoriality.

\section{Introduction}

The prior-residency effect is the effect that residents [i.e. individuals that are familiar with, and have invested in, a territory or environment] have a greater likelihood to dominate intruders or newcomers [i.e. individuals that are unfamiliar with a territory or environment upon meeting the resident] than vice versa (Braddock, 1949; Thinès \& Heuts, 1968; Heuts, 1979; Beaugrand et al., 1991, 1996; Heuts \& Nijman, 1998). It stems from a pay-off asymmetry between residents and intruders. The resident has invested more than the intruder in exploring its environment and in getting acquainted with its neighbours (when present), and will have more knowledge about its environment. Hence, the resident has more to loose that the intruder has to gain, and the resident may be able to use his knowledge of the environment to its advantage in dyadic conflicts with intruders. The more the resident has invested in its environment (e.g. higher tenure length, more complex environment) and the more valuable the environment is the stronger the prior-residency effect should be (Nijman \& Heuts, 2000; Johnsson \& Forster, 2002).

Kadry \& Barreto (2010) recently reported that in intruderresident tests with pearl cichlid, Geophagus brasiliensis, pairs in environmentally enriched test conditions [an aquarium with two pebbles and a plastic kelp model] showed lower frequencies of aggressive interactions than pairs in nonenriched test conditions [a barren aquarium]. Furthermore, they found that in non-enriched test conditions the frequency of directed attacks by resident fish was higher than that of intruders. They concluded that, unexpectedly, enrichment did not increase the probability that a pearl cichlid will dominate ('dominance' measured by them as superior attack frequency; this differs from the definition of dominance we used in our work on fish, see below).

Working with a cichlid, Kadry \& Barreto (2010) made reference to our work on another cichlid (Burton's mouthbreeder, Haplochromis burtoni) in intruder-resident tests in enriched and non-enriched conditions (Nijman \&

${ }^{1}$ Oxford Brookes University, School of Social Sciences and Law, Gipsy Lane, OX3 0BP Oxford UK. Email: vnijman@brookes.ac.uk ${ }^{2}$ University of Amsterdam, Swammerdam Institute for Life Sciences, Kruislaan 320, 1098 SM Amsterdam, the Netherlands 
Heuts, 2000). They reported that for this species we found the residents to have a greater dominance advantage in environmentally enriched conditions. In our study (Nijman \& Heuts, 2000) we included seven species of fish, and our overall finding was indeed that that for all species combined the prior-residency effect was significantly larger in enriched conditions than in non-enriched conditions.

Kadry \& Barreto (2010) highlighted our work on Burton's mouthbreeder. It is important to note, however, that in the same paper (Nijman \& Heuts, 2000) we presented data on two other cichlids, i.e. the Egyptian mouthbrooder, Pseudocrenilabrus multicolor and the striped kribensis, Pelvicachromis taeniatus. Previously one of us (Heuts, 1979, Heuts \& de Boer, 1973, de Boer \& Heuts, 1973) reported on the effect of environmental enrichment in resident-intruder interactions in a fourth cichlid, i.e. the jewel fish, Hemichromis bimaculatus.

Our aim is firstly to clarify some points in the work of Kadry \& Barretto (2010), especially where it pertains to our research, secondly to take this opportunity to present new information on the influence of environmental enrichment in resident-intruder interactions, and thirdly to offer some additional thoughts as why their results deviated from ours. We restrict our discussion to cichlids.

Kadry \& Barreto (2010) highlighted our results of environmental enrichment on the prior-residency effect in Burton's mouthbreeder. In fact we only reported a small difference in the prior-residency effect (albeit in the predicted direction) between enriched and non-enriched conditions for this species. In the enriched condition, in $82 \%$ of pairs $(9 / 11)$ was dominance gained by the resident and in the nonenriched condition this was in $73 \%$ of pairs (11/15) (two-tailed Fisher exact probability test, $\mathrm{P}=1.0$, Siegel, 1956). In the jewel fish the enrichment effect was more clear-cut yet not statistically significant (dominance was gained by residents in $80 \%$ of pairs (36/45) in the enriched condition and in the non-enriched condition dominance was gained by residents in $65 \%$ of pairs $(20 / 31)$ (two-tailed Fisher exact probability test, $\mathrm{P}=0.185)$. However, the effect of environmental enrichment in the remaining two species is more convincing (Fig. 1). For the Egyptian mouthbrooder dominance was gained by residents in $88 \%$ of pairs $(15 / 17)$ in the enriched condition and in the non-enriched condition dominance was gained by $56 \%$ of residents (9/16) (two-tailed Fisher exact probability test, $\mathrm{P}=0.057)$. In the striped kribensis the numbers were similar, i.e. $83 \%(15 / 18)$ vs 55\% (18/33) (two-tailed Fisher exact probability test, $\mathrm{P}=0.065$ ).

While Kadry \& Barreto (2010) conclude on the basis of their study that "the pearl cichlids reinforce this [residentintruder] paradigm irrespective of enrichment condition" we dully note that in their study neither of the two conditions taken separately, nor the pooled total, shows a significant prior-residency effect. In the non-enriched condition, in 7 out of 10 pairs did the resident win (binomial test, $\mathrm{P}=0.180$ ), in the enriched condition, in 3 out of 4 pairs did the resident win (binomial test, $\mathrm{P}=0.625$ ), and combined, in 10 out of 13 pairs

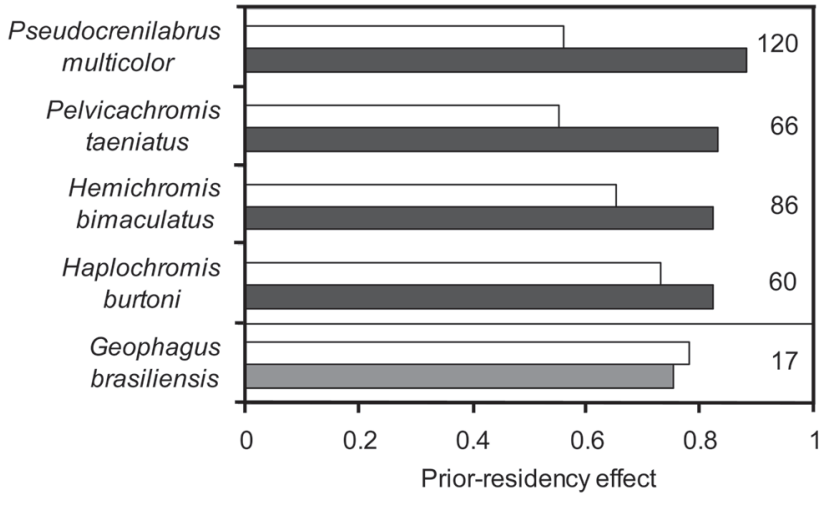

Fig. 1. Prior-residency effect in five species of cichlid fish in enriched (grey bars) and non-enriched test conditions (white bars), showing that for four species the prior-residency effect was larger in the enriched condition. Dark grey bars denote a significant prior-residency effect (binomial test, $\mathrm{P}<0.05$ ), and numbers on the right indicate the number of pairs tested for each species. Data from Geophagus brasiliensis are taken from Kadry \& Barreto (2010).

did the resident win (binomial test, $\mathrm{P}=0.092$ ). In the tests with the other cichlids we found a significant prior-residency effect for all four species when both test conditions (enriched and non-enriched) were pooled ( $\mathrm{P}$ between 0.0001 and 0.005 , binomial tests), and in most of the enriched test conditions ( $\mathrm{P}$ between 0.065 and 0.0001 ). In contrast, we did not find a significant prior-residency effect in the non-enriched conditions (P between 0.119 and 0.804).

Kadry \& Barreto (2010) remarked that "Nijman \& Heuts (2000) showed that resident fish (including the cichlid, $H$. burtoni) win more fights, and become the dominant fish, more frequently when reared in an enriched environment, absent of greater aggressiveness". While by and large correct, it is worthwhile to note that for the Egyptian mouthbrooder and the jewel fish in enriched conditions we did record significantly more attacks by residents relative to intruders compared to the non-enriched condition $\left(\chi^{2}=3.90, \mathrm{df}=1, \mathrm{P}=0.048\right.$, and $\chi^{2}=$ $4.15, \mathrm{df}=1, \mathrm{P}=0.042$, respectively).

Overall then, we found a marked prior-residency effect in four species of cichlids in enriched conditions but for none in the un-enriched conditions, with the contrast being marked for two species. In two species we found in clear contrast in the amount of aggressive behaviour displayed by residents vs intruders in the two environmental conditions, with increased levels of aggression in the enriched condition. In the other two species we did not find such an effect. In contrast, Kadry \& Barreto (2010) found no prior-residency effect for pearl cichlids but there was a clear difference in the amount of aggression displayed by both residents and intruders in the non-enriched condition. How to best explain these differences?

The first difference between Kadry \& Barreto's (2010) study and ours is the way how 'dominance' is established. 
Kadry \& Barreto's (2010) determined dominance by a dominance index which divides the number of attacks by a fish by the total number of aggressive interactions between that fish and a particular other fish. These data were collected during the first 15 minutes after introducing intruders to the resident. Hence, the individual that attacks the most during this period will be assigned as dominant partner. In our studies, dominance was determined by a succession of 'dominance signs', with each dominance sign consisting of an attack towards a particular other fish which is associated with, or immediately followed by, fleeing (or another submissive sign) of that other fish. Six dominance signs in succession (attack associated with fleeing) determine the dominant partner. Hence, it is not only the attack that matters but also, and importantly, the fleeing response of the attacked fish, and, further, the sequence in which this occurs. As reviewed by Zayan (1975) there seems to be a clear relation between aggression and dominance once a stable dominance hierarchy has become established (cf. Heuts 1979, Earley \& Dugatkin, 2006), but prior to dominance settlement this relationship seems to be absent. Hence, we do not think that aggression per se [or a derivative such as the dominance index] in the first 15 minutes after introducing the intruder to the resident is appropriate to define dominance.

These differences aside, accepting the prior-residency effect, in both the environmentally enriched and the unenriched condition we expect the resident to have a dominance advantage. The difference lies in the strength of the priorresidency effect, which should be greater in the enriched condition than in the un-enriched condition. With this in mind it is worthwhile to consider the size-effect (that is the proportion of pairs that showed dominance of one of the two pair members, i.e. a dominance decision). In our prior-residency experiments between $28 \%$ and $89 \%$ of the pairs resulted in a dominance decision, with sample sizes being between 60 and 120 pairs (Fig. 1); Kadry \& Barreto's (2010) were able to calculate a dominance index for $76 \%$ of their seventeen pearl cichlid pairs. Hence, in order to have a large enough sample to assess the effect of environmental enrichment in priorresidence situations testing more pairs may have been warranted in their study.

The results of Kadry \& Barreto (2010) and the results of our experiments highlighted here show that there is much to learn about the interrelationships between dominance and aggression and what influence the environment plays in this. We are encouraged by Kadry \& Barreto's focus on cichlids as we feel much of the previous research has focussed on too a restricted number of taxa, and, despite some reservations expressed above, we strongly support their quantitative work as the right approach in this endeavour.

\section{Acknowledgements}

Experiments were part of the Animal Behaviour courses SP240 and SP246 at the University of Amsterdam. We thank our students for help and for providing a stimulating and critical audience. Permission to conduct the experiments was granted to the late H. Albrecht, B. A. Heuts and V. Nijman by the Animal Experiment Commission (no. DED 40-1998).

\section{Literature Cited}

Beaugrand, J. P., C. Goulet \& D. Payette. 1991. Outcome of dyadic conflict in male green swordtail fish Xiphophorus helleri: effects of body size and prior dominance. Animal Behaviour, 41: 417424.

Beaugrand, J. P., D. Payette \& C. Goulet. 1996. Conflict outcome in male green swordtail fish dyads (Xiphophorus helleri): interactions of body size, prior dominance/subordination experience, and prior residency. Behaviour, 133: 303-319.

de Boer, J. N. \& B. A. Heuts. 1973. Prior exposure to visual cues affecting dominance in the Jewel fish Hemichromis bimaculatus Gill 1862 (Pisces, Cichlidae). Behaviour, 44: 299-321.

Braddock, J. C. 1949. The effect of prior residence upon the dominance in the fish Platypoecilus maculatus. Physiological Zoology, 22: 161-169.

Earley, R. L. \& L. A. Dugatkin. 2006. Merging social hierarchies: Effects on dominance rank in male green swordtail fish (Xiphophorus helleri). Behavioural Processes, 73: 290-298.

Heuts, B. A. 1979. Influencing agonistic behaviour in some fresh water fish by conspecifics and by familiarity with the environment [in Dutch with English summaries]. Unpublished Ph.D. thesis, University of Amsterdam, 532p.

Heuts, B. A. \& J. N. de Boer. 1973. Territory choice guided by familiar object cues from earlier territories in jewel fish, Hemichromis bimaculatus Gill 1862 (Pisces, Cichlidae). Behaviour, 45: 67-82.

Heuts, B.A. \& V. Nijman. 1998. Aggressive behaviour of two swordtail colour breeds (Xiphophorus, Poeciliidae) in a prior residence situation. Behavioural Processes, 43: 251-255.

Johnsson, J. I. \& A. Forser 2002. Residence duration influences the outcome of territorial conflicts in brown trout (Salmo trutta). Behavioral Ecology and Sociobiology, 51: 282-286.

Kadry, V. O. \& R. E. Barreto. 2010. Environmental enrichment reduces aggression of pearl cichlid, Geophagus brasiliensis, during resident-intruder interactions. Neotropical Ichthyology, 8: 329-332.

Nijman, V. \& B. A. Heuts. 2000. Effect of environmental enrichment upon resource holding power in fish in prior residence situations. Behavioural Processes, 49: 77-83.

Siegel, S. 1956. Nonparametric statistics for the behavioral sciences. Auckland, McGraw-Hill, 312p.

Thinès, G. \& B. A. Heuts. 1968. The effect of submissive experiences on dominance and aggressive behaviour of Xiphophorus (Pisces, Poeciliidae). Zeitschrift fur Tierpsychologie, 25: 139-154.

Zayan, R. C. 1975. Modification des effets liés à la priorité de résidence chez Xiphophorus (Pisces, Poeciliidae): le rôle des manipulations expérimentales. Zeitschrift für Tierpsychologie, 39: 463-491.

Submitted September 1, 2010

Accepted June 21, 2011

Published September 16, 2011 